\title{
The Genetics of Vestibular Schwannoma
}

\author{
Adam T. Hexter • D. Gareth Evans
}

Published online: 27 August 2014

(C) Springer Science+Business Media New York 2014

\begin{abstract}
Vestibular Schwannoma (VS) results from mutations/deletions of both copies of the NF2 gene on chromosome of 22q12, with lifetime risk estimated at one in 1,000. Bilateral VS is the hallmark of the autosomal dominant inherited tumour predisposition syndrome Neurofibromatosis type 2 (NF2), but the majority of VS are due to sporadic mutations. Estimations indicate that $33 \%$ of de novo patients with bilateral VS and up to $60 \%$ with unilateral VS have mosaicism for an NF2 mutation. Hundreds of mutations of the NF2 gene have been described, with truncating mutations (nonsense and frameshifts) leading to a severe phenotype. Despite advances in understanding, the relation between the genotype and phenotype in VS is not fully understood and the mechanisms leading to inactivation of the NF2 gene have not been fully characterised. As the genetics underlying VS is increasingly demystified targeted therapies offer hope in cases of progressive VS where existing treatment fails.
\end{abstract}

Keywords Vestibular Schwannoma - Genetics . Neurofibromatosis type $2 \cdot$ NF2 gene - Mutation . Genotype-phenotype correlation

\footnotetext{
A. T. Hexter $(\bowtie) \cdot$ D. G. Evans

Department of Genetic Medicine, Manchester Centre for Genomic Medicine, Manchester Academic Health Sciences Centre (MAHSC), University of Manchester, 6th Floor St Mary's Hospital, Oxford Road, Manchester M13 9WL, UK e-mail: adam.hexter@cmft.nhs.uk

D. G. Evans

e-mail: gareth.evans@cmft.nhs.uk
}

\section{Introduction}

Vestibular Schwannomas (VS) are benign tumours of the Schwann cell sheath arising from the vestibular branch of the eighth cranial nerve [1]. They have previously been referred to as "acoustic neuromas", reflecting the common clinical manifestation of hearing impairment. Nevertheless these lesions are not neuromas and the term VS more accurately reflects the tumour's cell and nerve of origin. There has been debate regarding the exact incidence of VS, and common wisdom is that the recent rising incidence represents improved detection of VS. The population incidence in the North West of England was recently estimated as being between 1 in $80-100,000$ per year, representing a lifetime risk of around one in 1,000 [2].

Neurofibromatosis type 2 (NF2), also previously referred to as central neurofibromatosis or bilateral acoustic neurofibromatosis, is an inherited multiple neoplasia syndrome with the hallmark being development of bilateral VS [3]. The birth incidence of NF2 is 1 in 33-40,000 [4]. NF2 patients can develop numerous nervous system tumours including Schwannomas, meningiomas, ependymomas, astrocytomas, and neurofibromas. In addition patients can develop peripheral neuropathy, ophthalmic pathology (cataracts, retinal hamartomas) and cutaneous tumours [5]. NF2, the first case of which was reported in 1822 by Wishart [6], typically presents between the ages of 16-30 as a result of the pressure effects of VS, classically with unilateral hearing impairment, tinnitus or imbalance. However, the presentation of NF2 in childhood is more likely to be related to non-VS lesions [7], such as cutaneous or visual manifestations. Only $5 \%$ of VS cases are associated with NF2 [3], with the vast majority of cases due to sporadic mutations. NF2 remains a devastating diagnosis with substantial morbidity and despite advancements in 
imaging modalities and surgical techniques, over $90 \%$ of NF2 patients die early either from the disease or the effects of its treatment [8].

Neurofibromatosis type 1 (NF1), previously known as von Recklinghausen's disease, is a genetically and phenotypically distinct syndrome with autosomal dominance inheritance. NF1 occurs as a result of genetic abnormalities of the NF1 gene on chromosome 17q11 [9]. Clinical features are diverse and include café-au-lait spots, Lisch nodules, optic pathway gliomas, bony dysplasia and cutaneous neurofibromas. VS do not form part of the NF1 diagnosis and do not occur at increased frequency. In 1987 the formal delineation between NF1 and NF2 was defined at the National Institutes of Health consensus meeting [10].

In this review we discuss current knowledge of the genetics of VS. We focus on recent developments in understanding and explore the controversial discoveries and current hypotheses of interest.

\section{Search for the Gene}

The NF2 gene was first identified in 1993 following extensive genetic mapping. Seizinger et al. [11] studied the DNA of patients with unilateral VS using polymorphic DNA markers and found that loss of constitutional heterozygosity was commonly seen in NF2 patients. Seizinger later reinforced the finding of loss of genes in chromosome 22 in patients with VS and other NF2-related tumours [12]. This led to the subsequent chromosomal localisation of the $N F 2$ gene to the centre of the long arm of chromosome 22 and then its cloning simultaneously by two separate groups: Trofatter et al. [13] and Rouleau et al. [14]. Specifically the $N F 2$ gene resides on chromosome 22 , band 22q12.2, from nucleotide 29999545 to 30094589 . The gene's promoter region and major transcription initiation site have subsequently been described [15].

The gene product is a $69 \mathrm{kDa}$ protein that forms part of the band 4.1 family of cytoskeleton-associated proteins known as ERM proteins [13, 14]. The gene product has most commonly been referred to as Merlin, reflecting an acronym of the first letters of moesin-, ezrin-, radixin-like protein [13]. Merlin has 595 amino acids with three functional domains: an amino terminal domain (exons 1-9), an $\alpha$ helical domain (exons 10-13), and a carboxy terminal domain (exons 14-17) [16]. Hence the NF2 gene consists of 17 exons and with the effect of alternative splicing it has two predominant isoforms. Merlin is expressed ubiquitously in human tissues, but there is considerable expression in the Schwann cell plasma membrane, meningeal cells and neuronal tissue [17]. Unlike other ERM proteins that generally function to facilitate growth, Merlin has been shown to have an important suppressive role in the regulation of cell proliferation [18]. The regulation of Merlin itself is by phosphorylation, with phosphorylation by kinases causing inactivation of Merlin; whereas dephosphorylation by phosphatases allows Merlin to adopt its active state [18].

\section{Inheritance Pattern}

Gardner and Frazier [19] first demonstrated that NF2 has an autosomal dominant transmission in 1930 in a family of 38 affected members spanning five generations. The NF2 gene is a tumour suppressor gene and only when both alleles of the gene are inactivated will tumours form. To develop the disease an affected patient only has to have a mutation in one copy of the NF2 gene because the likelihood of a second hit in a Schwann cell particularly on the vestibular nerve appears extremely high. Patients who develop VS can either have inherited a germline mutation of one affected allele (inherited NF2) or alternatively acquire a de novo mutation of an allele that is not inherited. Tumours occur in cells that experience silencing in both copies of $N F 2$, specifically in the wild type $N F 2$ allele in someone with NF2. The susceptible target organs are those with high Merlin expression. NF2 has extremely high penetrance by 60 years of age [20], which means a patient who inherits an abnormal copy of the NF2 gene will nearly always develop clinical NF2 by the age of 60. Approximately half of NF2 cases have no family history, and they signify new germline mutations that were not inherited [20]. This has fundamental implications on the risk of vertical transmission. Transmission from parents with an inherited germline mutation has an autosomal dominant inheritance pattern and the likelihood is therefore $50 \%$. However, the risk of transmission of those with a de novo mutation is substantially lower. In cases of de novo neurofibromatosis type 2 and negative blood mutation analysis, a recent study revealed transmission rates of 1 in 8 for patients with bilateral VS and 1 in 12 for patients with unilateral VS [21]. The risk decreases further if the age of onset of symptoms is older [22]. Unilateral isolated VS are usually due to sporadic mutations whereas bilateral VS are practically always due to NF2. There is nonetheless a 1 in 2 million chance that an individual could develop bilateral VS by chance [23] in their lifetime, equating to approximately 30 people in the UK and 150 in the USA alive today. Sporadic VS tend to grow slowly and has an older age of onset when compared with NF2-associated VS, which occur in younger patients and exhibits faster rates of growth. 


\section{Mosaicism}

The presence of a mutation or chromosomal abnormality in a subpopulation of cells is referred to as mosaicism [24]. This scenario results from a de novo mutation of an allele at the post-zygotic stage of embryogenesis, thus generating two distinct cell lineages. In 1995 Bourn et al. [25] made the first report of mosaicism in the NF2 gene. The investigators observed that the mild phenotype was associated with the warm spot alteration $169 \mathrm{C}>\mathrm{T}$ in approximately $10 \%$ of blood cells of a mosaic patient compared with a non-mosaic patient displaying a severe phenotype with the identical mutation. The clinical severity in mosaic NF2 is related to the time when the mutation took place during development. Early mutations result in more cells being affected and consequently are associated with a more severe phenotype. Generally patients with mosaicism display a mild phenotype, with either localised or mild generalised disease [21].

One of the characteristics of NF2 is the high rate of mosaicism amongst de novo cases. Reports have suggested that $33 \%$ of de novo patients who present with bilateral VS and up to $60 \%$ of such patients who present with unilateral VS have mosaicism [24]. Kluwe et al. [26] showed the rate of mosaicism to be at least $24.8 \%$ in a cohort of 233 NF2 patients with bilateral VS. In approximately half of mosaics the mutation is detectable in blood lymphocytes, whereas in the remainder the genetic abnormality is only detectable upon tumour tissue analysis. The asymmetric presentation of NF2 is a classical feature of mosaicism if the mutation cannot be detected in their blood cells. However, individuals presenting with unilateral VS at a young age might well have mosaicism for NF2 and later go on to develop full-blown NF2 [27, 28]. This is important to bear in mind when counselling patients with unilateral VS about the risks of developing additional tumours.

Unlike germline NF2, the risk of transmitting NF2 in mosaic patients to offspring is negligible. In the unlikely event that an NF2 mutation is inherited from a mosaic parent the child will host the mutation in all their cells and will develop a severe phenotype. Some reports have suggested a degree of anticipation in NF2 [29]. This most likely represents cases where mosaic patients have transmitted the disease to their offspring, who subsequently develop a severe phenotype. Hence there remains minimal evidence for anticipation in NF2.

\section{Mutational Spectrum of NF2}

The loss of $22 \mathrm{q} 12$ locus harbouring the $N F 2$ gene is the only genetic alteration reported in both sporadic and NF2associated VS $[13,14]$. The fact that the majority of NF2 cases are sporadic highlights the high mutation rate of $N F 2$, a gene also implicated in the tumourigenesis of meningiomas and other non-VS tumours [30, 31]. There has been considerable progression in our understanding of what mutations occur in the NF2 gene and mutation analysis techniques have identified hundreds of possible mutations [32]. The frequencies of the different types of mutations in our database [33] at the time of writing can be seen in Table 1, with the commonest type being point mutations and complex rearrangements (large single or multi-exon

Table 1 Mutations found in germline and tumour in the Manchester (UK) genetics laboratory

\begin{tabular}{|c|c|c|c|c|}
\hline & $\begin{array}{l}\text { NF2 VS first hit } \\
\text { (germline) }\end{array}$ & NF2 VS second hit & $\begin{array}{l}\text { Sporadic VS } \\
\text { first hit }\end{array}$ & $\begin{array}{l}\text { Sporadic VS } \\
\text { second hit }\end{array}$ \\
\hline \multicolumn{5}{|l|}{ Point mutations } \\
\hline Nonsense & $155(29 \%)$ & $3(2.0 \%)$ & $29(22 \%)$ & $3(2.5 \%)$ \\
\hline Frameshift insertions/deletions & $125(25 \%)$ & $9(6.0 \%)$ & $37(28 \%)$ & $7(5.5 \%)$ \\
\hline Missense & $24(4.5 \%)$ & 0 & $1(7.5 \%)$ & $1(1 \%)$ \\
\hline In-frame deletions & $5(1.0 \%)$ & 0 & $1(7.5 \%)$ & 0 \\
\hline Splice site & $115(22 \%)$ & $5(3.5 \%)$ & $13(10 \%)$ & $3(2.5 \%)$ \\
\hline \multicolumn{5}{|l|}{ Large rearrangements } \\
\hline Ring 22 & $3(0.5 \%)$ & $\mathrm{NA}^{\mathrm{a}}$ & $\mathrm{NA}^{\mathrm{a}}$ & $\mathrm{NA}^{\mathrm{a}}$ \\
\hline Chromosome translocation & $2(0.5 \%)$ & $\mathrm{NA}^{\mathrm{a}}$ & $\mathrm{NA}^{\mathrm{a}}$ & $\mathrm{NA}^{\mathrm{a}}$ \\
\hline MLPA exon/multiexon deletions/duplications & $102(19 \%)$ & $3(2.0 \%)$ & $2(1.5 \%)$ & $2(1.5 \%)$ \\
\hline Loss of chromosome $22 \mathrm{q}$ or most all chromosome & 0 & $80(55 \%)$ & 0 & $70(53 \%)$ \\
\hline Mitotic recombination & 0 & $20(14 \%)$ & 0 & $9(7.0 \%)$ \\
\hline Methylation & 0 & 0 & 0 & 0 \\
\hline Total & $n=531$ & $n=146$ & $n=131$ & $n=131$ \\
\hline
\end{tabular}

${ }^{a}$ Karyotypic analysis is required for this measurement but this has not yet been performed on tumours. The order of mutations in sporadic VS cannot be determined with certainty but is assumed to be a point mutation first if one is present 
deletions and duplications). Balanced chromosomal $(n=2)$ translocations that disrupt the NF2 gene have also been described as causing NF2 but in general such gross chromosomal changes are uncommon [34]. Ring 22 is another inherited defect that can lead to NF2 [34, 35] and it is classically associated with mental retardation. Loss of heterozygosity $(\mathrm{LOH})$ is a common feature found in the majority of sporadic Schwannomas. Loss of function of the second copy of the NF2 gene may occur by the same point mutations that occur in the germline, by large single or multi-exon deletions or duplications, by loss of the whole chromosome 22 or $22 \mathrm{q} 12$ locus, or by mitotic recombination (both the latter events cause LOH) [36].

\section{Genotype-Phenotype Correlations}

The disease severity of NF2 has traditionally been divided into subgroups depending on the age of onset of symptoms and the presence of non-VS intracranial and spinal tumours. The age of onset and age of diagnosis have been shown to be the two most important predictors of growth rates of VS in NF2 [8]. The severe "Wishart" form of NF2 is associated with an early age of onset, rapid course and numerous non-VS intracranial and spinal tumours in addition to bilateral VS [6]. The mild "Gardner" form describes a less aggressive type of NF2, associated with a later age of onset and a lower incidence of intracranial tumours [19].

Considerable effort has been made to establish correlations between specific mutations and specific phenotypes (Table 2). Early reports showed that missense mutations, large deletions and in-frame mutations are typically associated with the milder form of disease [37]. Somatic mosaicism is also associated with a mild phenotype. However, frameshift mutations and nonsense mutations that result in truncation of the $N F 2$ gene product are associated with a more severe phenotype, thought to be due to the formation of a smaller and non-functional protein product [37]. Truncating mutations are seen more frequently in mosaic patients than in inherited cases, something that has been attributed to the reduced genetic fitness of inherited cases. Likewise the so-called milder mutations, such as missense mutations, are rarely seen in mosaic individuals but are relatively frequent in inherited cases [38]. In one of the first large-scale studies [39] into genotype-phenotype correlations 42 patients with classical NF2 resulting from truncating mutations had an average age of onset of symptoms at 19 years and a diagnosis at 22.4 years compared with an average age of onset of symptoms at 27.8 years and a diagnosis at 23.4 years seen
Table 2 Leading reports of genotype-phenotype correlations in NF2

\begin{tabular}{ll}
\hline Study & $\begin{array}{l}\text { No. NF2 } \\
\text { patients }\end{array}$ \\
\hline Merel [70] & 91 unrelated \\
Kluwe [71] & 59 unrelated \\
$\begin{array}{cc}\text { Ruttledge } \\
\text { [72] }\end{array}$ \\
$\begin{array}{c}111(73 \\
\text { families) }\end{array}$ \\
Parry [73] & $\begin{array}{c}32 \text { unrelated } \\
\text { patients }\end{array}$
\end{tabular}

Kluwe [24] 16 inherited, 91 sporadic Genotype-phenotype correlation observed

Kluwe [74] 87 unrelated
patients
Mutations that preserved the carboxy terminal domain were associated with a mild phenotype

\section{Evans [39] 142 families}

Frameshift and nonsense mutations were associated with a more severe phenotype than missense mutations

Truncating mutations typically exhibited more severe phenotypes and had poorer clinical outcomes

Nonsense/frameshift mutations were associated with a higher frequency and number of tumours and a younger age at onset and diagnosis

Identification of mutations in sporadic NF2 is more likely in patients with severe phenotypes when compared with mild phenotypes ( $p=0.007$ )

Mutations downstream from exon 8 in the NF2 gene were associated with milder phenotypes

$\begin{array}{ll}\begin{array}{c}\text { Patronas } \\ \text { [40] }\end{array} & 49 \\ \text { Baser [75] } & 18 \text { (inherited) } \\ \text { Baser [8] } & \begin{array}{c}368 \text { (261 } \\ \text { families) }\end{array}\end{array}$

Truncating mutations demonstrated a younger age at onset $(p<0.001)$ and were more likely to have symptomatic non-VS tumours $(p<0.001)$

Nonsense and frameshift mutations were associated with a higher mean frequency of intramedullary and spinal canal tumours $(p<0.001)$

\begin{tabular}{|c|c|c|}
\hline Baser [76] & 406 & $\begin{array}{l}\text { Nonsense or frameshift mutations } \\
\text { were associated with a higher } \\
\text { number of tumours than other } \\
\text { mutation types }\end{array}$ \\
\hline Baser [41] & $\begin{array}{l}831 \text { (528 } \\
\text { families) }\end{array}$ & $\begin{array}{l}\text { Splice-site mutations located in exons } \\
1-5 \text { were associated with a more } \\
\text { severe phenotype than mutations in } \\
\text { exons } 11-15\end{array}$ \\
\hline $\begin{array}{l}\text { Selvanathan } \\
\text { [38] }\end{array}$ & 268 & $\begin{array}{l}\text { Truncating mutations were associated } \\
\text { with a more severe phenotype, } \\
\text { reflected by a younger age of VS } \\
\text { diagnosis }(p=0.007) \text { and a higher } \\
\text { prevalence of non-VS tumours } \\
(p<0.006)\end{array}$ \\
\hline Smith [31] & 411 & $\begin{array}{l}\text { The position of the NF2 mutation } \\
\text { affected occurrence of cranial } \\
\text { meningiomas: cumulative risk to } \\
\text { age } 50 \text { years was } 70 \% \text { for exons } \\
1-3 \text { compared with } 28 \% \text { for exons } \\
14-15\end{array}$ \\
\hline
\end{tabular}

Growth rates of VS were not affected by mutation type

Constitutional missense mutations were associated with a lower risk of mortality when compared with all

Nonsense or frameshift mutations were associated with a higher number of tumours than other plice-site mutations located in exons 1-5 were associated with a more severe phenotype than mutations in

Truncating mutations were associated diagnosis $(p=0.007)$ and a higher prevalence of non-VS tumours

The position of the NF2 mutation pected occurrence of cranial age 50 years was $70 \%$ for exons 1-3 compared with $28 \%$ for exons 
in 51 patients with missense, large deletion or splice-site mutations. Truncating mutations have been associated with a higher prevalence of meningioma when compared with missense and splice-site mutations [38]. Patronas et al. [40] found that truncating and nonsense mutations are associated with increased prevalence of spinal tumours when they performed MRI spines in 49 patients with NF2. These genotype-phenotype correlations correspond to the relative risk of mortality for different mutations, with nonsense or frameshift mutations having a higher mortality than missense mutations [8].

Smith et al. [31] investigated the genetic aberrations in a cohort of 411 NF2 patients, which indicated that the location of the mutation in the NF2 gene affected the likelihood of meningioma and this was true across all mutation types. The cumulative risk of cranial meningioma to age 50 years was $70 \%$ for exons 1-3 compared with $28 \%$ for exons 14-15. The authors argued that this positional effect provides evidence that not all truncated products are nonfunctional. Baser et al. [41] evaluated genotype-phenotype correlations in 831 patients from 528 NF2 families with constitutional NF2 mutations and observed a positional effect, with splice-site mutations in exons 11-15 appearing to be associated with less severe disease and younger age at onset of symptoms than mutations in exons 1-5. However, splice-site mutations are generally thought to have a less predictable correlation with phenotype than other types of mutations. Despite these recognised trends, there have been conflicting reports that break the norm. Large deletions that involve the whole $N F 2$ gene have been identified in patients with mild phenotypes yet simple missense and frameshift mutations have been observed in severely affected cases [42]. Hence there is no "one-size-fits-all" rule with genotype-phenotype correlations and other mechanisms must be involved in the inactivation of the NF2 gene and determining the phenotype severity. This notion is further supported by reports of phenotypic variability within NF2 families hosting the same mutation [43] and monozygotic twins harbouring the same mutation but showing distinct variations in phenotype [44]. Bruder et al. [45] proposed the presence of a "modifier gene" being a possible mechanism for inactivation of the $N F 2$ gene, when they observed that deletions in people with the severe form of NF2 often extended onto the telomeric side to the $N F 2$ gene, whereas patients with mild phenotypes had mutations that were limited to the NF2 locus itself.

\section{Is NF2 the Only Gene?}

Zucman-Rossi et al. [46] carried out extensive genetic analysis of 19 patients with VS but identified mutations in only $84 \%$ of patients. In the remaining $16 \%$ of patients the genetic mechanism leading to the development of NF2 could not be determined. However, when the second generation of an NF2 family is assessed mutation detection in the germline rises to at least $91 \%$ on DNA analysis of blood (84/92) [21]. This was boosted to 101/108 (93\%) in a recent report [1] and is currently 133/141 (94\%). Two of the six mutations unfound on DNA analysis have been identified on RNA [1]. As such it seems unlikely that there is another gene that causes classical NF2.

\section{Mechanisms of Gene Inactivation}

There are notable similarities and differences between the distribution and type of germline and somatic NF2 mutations (Table 1). The first hit in the germline and in sporadic VS is usually a point mutation (nonsense, frameshift deletion/insertion, splice-site in-frame deletion or missense mutation). However, large single or multi-exon deletions are common, especially in the germline. Second hits are typically chromosome loss events but this can also occur by mitotic recombination without genetic material loss where a mutation is doubled up on each copy of chromosome 22 . Finally methylation appears to occur in at least a proportion of sporadic VS.

A recent report showed that nonsense mutations are more common than frameshift mutations by a ratio of $1.3: 1$ when analysing germline mutations of the NF2 gene. However, analysis of somatic mutations reveals a reversal of this ratio [47]. When considering NF2 nonsense mutations in both scenarios, the most frequently observed single base-pair transitions is $\mathrm{C}>\mathrm{T}$. With regards to sporadic meningioma, there is a notable absence of mutations in exons 14 and 15, and mutations in this region correlate with a considerably lower meningioma risk in NF2 [31]. A recently reported mutational mechanism is the increasing change from predominance of nonsense mutations in the germline and early somatic mutations to a preponderance of frameshift mutations in the tumours of older patients with sporadic VS [47]. This age-related shift in the mutation spectra of germline is likely to represent deficiencies in certain DNA repair pathways in older individuals [47]. Although the great majority if not all VS development requires inactivation of the $N F 2$ gene, there has been no report to date that demonstrates $100 \%$ involvement of $N F 2$, with aberrations confirmed in both copies of the gene. One possible reason for this is the heterogeneity of mechanisms that can lead to inactivation of the NF2 gene. Involvement of the $N F 2$ can be detected in approximately 80-90\% of Schwannomas when using conventional approaches of mutational analysis of sequencing and $\mathrm{LOH}$. However, such approaches detect aberrations of both NF2 genes in only 50-60\% of cases. Similarly there are diverse 
mechanisms for $\mathrm{LOH}$ inactivation, with most instances demonstrating loss of chromosome 22 (or at least its long arm) but some cases have been shown to result from mitotic recombination [36, 47]. Indeed NF2 inactivation in Schwannomatosis is now thought to be partly due to mitotic recombination.

Another hypothesised mechanism for NF2 inactivation is epigenetic modifications, such as hypermethylation [48, 49]. Gonzalez Gomez et al. [48] examined the DNA methylation profile of Schwannomas in 44 sporadic or NF2-associated Schwannomas using methylation-specific PCR. They identified 5 tumour-related genes most frequently methylated in VS cases that were unaffected in non-VS controls. The finding that the $5^{\prime}$ and $3^{\prime}$ flanking regions of the human $N F 2$ locus are $\mathrm{G} / \mathrm{C}$ rich and potential sites for gene methylation and inactivation adds weight to the possibility of epigenetic factors playing a role in VS tumourigenesis. Methylation in a manner such as that described for TP16 could involved both copies of NF2, which would account for the reason why some tumours do not exhibit point mutations or $\mathrm{LOH}$ on standard approaches of mutational analysis.

Until recently VS was considered an exclusion criteria for the related condition Schwannomatosis [50]. However, recent evidence suggests that VS can indeed be a feature of Schwannomatosis [51•]. The identification of mutations in the LZTR1 gene on 22q has now shown that this gene may predispose to the development of VS [52]. Findings such as these make it appear increasingly likely that there are other tumour suppressor genes of $22 \mathrm{q}$ that have a role in the formation of VS. Future work must focus on discovering these genes and ascertaining how they play a role in the tumourigenesis of VS and other non-VS tumours.

Although NF2 loss is the fundamental driver of VS formation it is likely from mouse and human modelling that further hits in other genes are necessary and that a simple two hit cause is insufficient [53]. Chromosome and genomic array studies have shown low levels of loss and gain of material apart from 22q [54] and expression arrays have shown a variety of aberrant expression. MET and associated genes, such as integrin, alpha 4 (ITGA4)/B6, PLEXNB3/SEMA5 and caveolin-1 (CAV1) showed patterns of deregulation in VS. Additionally, androgen receptor (AR) down-regulation may denote a hormonal effect or cause in VS. The osteopontin gene (SPP1), which is involved in merlin protein degradation, was up-regulated in some tumours [55].

\section{Targeted Therapy in VS}

With the emergence of the era of targeted therapies in oncology, there has been increasing interest into the molecular mechanisms underlying VS tumourigenesis. The functions of the Merlin are becoming increasingly characterised. Merlin is known to play a role in three important processes: firstly cell-to-cell adhesion via interaction with proteins such as $\beta 1$ integrin and $\beta$ catenin; secondly membrane organisation via effects on proteins such as CD44 and the epidermal growth factor receptor (EGFR); and finally influencing intracellular pathways via cytosolic proteins such as phosphatidylinositol 3-kinase [56]. This was demonstrated in mouse models, where overexpression of the NF2 gene limited cell growth in Schwannoma cells [57]. Distortions in the actin cytoskeleton and abnormalities in cell spreading are seen in Schwannoma cells from NF2 tumours [58]. Welling et al. [59] identified 42 genes that were significantly up-regulated in 6 cases of VS using microarray DNA analysis. These included mediators of angiogenesis and cell migration. At present having knowledge of genotype in VS does not allow reliable prediction of tumour behaviour. However, it is hoped that by identifying the pathways that are abnormal through cDNA microarray analysis it will allow better predictions of clinical behaviour and allow pharmacological targeting of the oncogenic drivers. Proof of concept has been achieved in early clinical trials. Plotkin et al. [60] treated 10 patients with VS that expressed Vascular Endothelial Growth Factor (VEGF) with the anti-VEGF pharmaceutical, Bevacizumab. In nine cases the VS shrank in size, with a median best response being a $26 \%$ volumetric reduction. Follow up of 31 NF2 patients with progressive VS patients has confirmed a benefit of targeted therapy, with Bevacizumab treatment leading to hearing improvement and tumour shrinkage in over $50 \%$ of cases [61•]. However, the same benefit has not been seen with meningiomas associated with NF2, with Bevacizumab treatment achieving only a temporary improvement in tumour size. An explanation for this finding is that VEGF pathways are not the foremost drivers for angiogenesis in meningiomas [62]. In addition to angiogenesis, other signalling pathways have been shown to be important in VS growth. Murine models where the NF2 genes have been knocked out show lack of contact inhibition. However, when these cells are treated with anti-EGFR therapies contact inhibition is restored [63]. Hence it appears EGFR pathways are involved in VS progression and a recent consensus conference highlighted this family of receptors as attractive targets in cases of progressive VS associated with NF2 [64]. It is likely that more than one pathway is involved in VS tumourigenesis and therefore drugs that target multiple pathways are an attractive proposition. Combination therapy targeting the VEGF and EGFR pathways with VEGFR2/EGFR inhibitors has shown anti-tumour activity in murine models [65]. A recent breakthrough for targeted therapy in VS was when Bevacizumab was approved for the use in strict situations in the English nationally commissioned service [66]. There is need for future clinical trials to determine the optimum doses and 
duration of targeted therapies for VSs and other NF2-related tumours, although to date targeted therapies have largely been well tolerated in clinical pilots. Although personalised therapy has not generally translated to clinical practice as yet, it is possible that these new avenues of treatment will provide alternatives to the existing treatment options of untreated observation of tumour growth, stereotactic radiation and surgical intervention. It is hoped that in the future the management of aggressive VS will be based on a molecular classification, whereby the prominent signalling pathways responsible for tumourigenesis are targeted pharmacologically [67]. This personalised approach has been employed with success in other neoplasms, such as leukaemias and solid tumours of the bowel and breast [68, 69].

\section{Conclusion}

VS results from genetic aberrations of the $N F 2$ gene on chromosome of $22 \mathrm{q} 12$, most of which are due to sporadic mutations although approximately $5 \%$ occur as part of the tumour predisposition syndrome NF2. Genotype-phenotype correlations have been described, with truncating mutations (the most frequent germline event) being associated a more severe phenotype. Recent progress in cellular research has identified signalling pathways in which the $N F 2$ gene product is involved. It is hoped new tailored drug therapies will take advantage of the increasing knowledge of the genetics of VS and might revolutionise the management and outcome for the condition.

\section{Compliance with Ethics Guidelines}

Conflict of Interest Adam Hexter declares that he has no conflict of interest. D. Gareth Evans declares that he has no conflict of interest.

Human and Animal Rights and Informed Consent Human studies were done by authors. This review article includes some studies with human subjects performed by the authors. This was with research ethics committee approval. With regard to the authors' research cited in this paper, all procedures were followed in accordance with the ethical standards of the responsible committee on human experimentation and with the Helsinki Declaration of 1975, as revised in 2000 and 2008.

\section{References}

Papers of particular interest, published recently, have been highlighted as:

- Of importance

1. Evans DG. Neurofibromatosis type 2 (NF2): a clinical and molecular review. Orphanet J Rare Dis. 2009;4(1):16.
2. Evans DG, Moran A, King A, et al. Incidence of vestibular Schwannoma and neurofibromatosis 2 in the North West of England over a 10-year period: higher incidence than previously thought. Otol Neurotol. 2005;26(1):93-7.

3. Evans DG. Neurofibromatosis 2 [Bilateral acoustic neurofibromatosis, central neurofibromatosis, NF2, neurofibromatosis type II]. Genet in Med. 2009;11(9):599-610.

4. Evans DG, Howard E, Giblin C, et al. Birth incidence and prevalence of tumor-prone syndromes: estimates from a UK family genetic register service. Am $\mathrm{J}$ Med Genet A. 2010;152(2):327.

5. Asthagiri AR, et al. Neurofibromatosis type 2. The Lancet. 2009;373(9679):1974-86.

6. Wishart JH. Case of tumours in the skull, dura mater, and brain. Edinburgh Med Surg J. 1822;18:393-7.

7. Evans DG, Birch JM, Ramsden RT. Paediatric presentation of type 2 neurofibromatosis. Arch Dis Child. 1999;81(6):496.

8. Baser ME, Friedman JM, Aeschliman D, et al. Predictors of the risk of mortality in neurofibromatosis 2. Am J Hum Genet. 2002;71(4):715-23.

9. Shen MH, Harper PS, Upadhyaya M. Molecular genetics of neurofibromatosis type 1 (NF1). J Med Genet. 1996;33(1):2-17.

10. National Institutes of Health Consensus Development Conference. Statement on Neurofibromatosis. Arch Neurol. 1987; 45(5):575-578.

11. Seizinger BR, Martuza RL, Gusella JF. Loss of genes on chromosome 22 in tumorigenesis of human acoustic neuroma. Nature. 1986;322:644-7.

12. Seizinger BR, Rouleau G, Ozelius LJ, Lane AH, St George-Hyslop P, Huson S, Gusella JF, Martuza RL. Common pathogenetic mechanism for three tumor types in bilateral acoustic neurofibromatosis. Science. 1987;236(4799):317-9.

13. Trofatter JA, MacCollin MM, Rutter JL, Murrell JR, Duyao MP, Parry DM, Eldridge R, et al. A novel moesin-, ezrin-, radixin-like gene is a candidate for the neurofibromatosis 2 tumour suppressor. Cell. 1993;72(5):791-800.

14. Rouleau GA, Mere IP, Lutchman M, Sanson M, Zucman J, Marineau C, HoangXuan $\mathrm{K}$, et al. Alteration in a new gene encoding a putative membrane-organising protein causes neurofibromatosis type 2. Nature. 1993;363:515-21.

15. Kino $\mathrm{T}$, et al. Identification of the cis-acting region in the NF2 gene promoter as a potential target for mutation and methylation dependent silencing in Schwannoma. Genes Cells. 2001;6(5):441-54.

16. Pećina-Šlaus N. Merlin, the NF2 gene product. Pathol Oncol Res. 2013;19(3):365-73.

17. Hanemann CO. Magic but treatable? Tumours due to loss of merlin. Brain. 2008;131(3):606-15.

18. Neff BA, et al. The molecular biology of vestibular Schwannomas: dissecting the pathogenic process at the molecular level. Otol Neurotol. 2006;27(2):197-208.

19. Gardner WJ, Frazier CH. Bilateral acoustic neurofibromas: a clinical study and field survey of a family of five generations with bilateral deafness in thirty eight members. Arch Neurol Psychiatry. 1930;23:266-302.

20. Evans DG, Huson SM, Donnai D, et al. A genetic study of type 2 neurofibromatosis in the United Kingdom. I. Prevalence, mutation rate, fitness, and confirmation of maternal transmission effect on severity. J Med Genet. 1992;29(12):841-6.

21. Evans D, Gareth R, et al. Mosaicism in neurofibromatosis type 2: an update of risk based on uni/bilaterality of vestibular Schwannoma at presentation and sensitive mutation analysis including multiple ligation-dependent probe amplification. J Med Genet. 2007;44(7):424-8.

22. Evans DG, Wallace A. An update on age related mosaic and offspring risk in neurofibromatosis 2 (NF2). J Med Genet. 2009;46(11):792. 
23. Wu C-L, Neary W, Thakker N, Black G, Lye R, Read A, Ramsden RT, Evans DGR. Differential diagnosis of type 2 neurofibromatosis: molecular discrimination of NF2 and sporadic vestibular Schwannomas. J Med Genet. 1998;35(12):973-7.

24. Kluwe L, Mautner VF. Mosaicism in sporadic neurofibromatosis 2 patients. Hum Mol Genet. 1998;7(13):2051-5.

25 . Bourn D, et al. A mutation in the neurofibromatosis type 2 tumorsuppressor gene, giving rise to widely different clinical phenotypes in two unrelated individuals. Am J Hum Genet. 1994;55(1):69.

26. Kluwe L, et al. Molecular study of frequency of mosaicism in neurofibromatosis 2 patients with bilateral vestibular Schwannomas. J Med Genet. 2003;40(2):109-14.

27. Mohyuddin A, Neary WJ, Wallace A, et al. Molecular genetic analysis of the NF2 gene in young patients with unilateral vestibular Schwannomas. J Med Genet. 2002;39(5):315-22.

28. Evans DG, Raymond FL, Barwell JG, Halliday D. Genetic testing and screening of individuals at risk of NF2. Clin Genet. 2012;82(5):416-24.

29. Kanter WR, Eldridge R, Fabricant R, Allen JC, Koerber T. Central neurofibromatosis with bilateral acoustic neuroma: genetic, clinical and biochemical distinctions from peripheral neurofibromatosis. Neurology. 1980;30(8):851.

30. Welling DB, Guida M, Goll F, et al. Mutational spectrums in the neurofibromatosis type 2 gene in sporadic and familial Schwannomas. Hum Genet. 1996;98(2):189-93.

31. Smith MJ, et al. Cranial meningiomas in 411 neurofibromatosis type 2 (NF2) patients with proven gene mutations: clear positional effect of mutations, but absence of female severity effect on age at onset. J Med Genet. 2011;48(4):261-5.

32. Ahronowitz I, Xin W, Kiely R, Sims K, MacCollin M, Nunes FP. Mutational spectrum of the NF2 gene: a meta-analysis of 12 years of research and diagnostic laboratory findings. Hum Mutat. 2007;28(1):1-12.

33. Manchester Centre for Genomic Medicine, University of Manchester, Manchester Academic Health Sciences Centre (MAHSC), UK.

34. Tsilchorozidou T, Menko F, Lalloo F, Kidd A, Da Silva R, Smith P, Malcolmson A, Dore J, Madan K, Brown A, Yovos JG, Tsaligopoulos M, Vogiatzis N, Wallace A, Evans DGR. Constitutional rearrangements of chromosome 22 as a cause of neurofibromatosis type 2. J Med Genet. 2004;41(7):529-34.

35. Denayer E, Brems H, de Cock P, Evans GD, Van Calenbergh F, Bowers N, Sciot R, Debiec-Rychter M, Vermeesch JV, Fryns JP, Legius E. Pathogenesis of vestibular Schwannoma in ring chromosome 22. BMC Med Genet. 2009;10(1):97.

36. Hadfield KD, Smith MJ, Urquhart JE, Wallace A, Bowers NL, Trump D, Newman WG, Evans DG. Differences in rates of loss of heterozygosity and mitotic recombination in NF2 Schwannomas, sporadic vestibular Schwannomas and Schwannomatosis Schwannomas. Oncogene. 2010;29(47):6216-21.

37. Eldridge R, Parry DM, Kaiser-Kupfer MI. Neurofibromatosis 2: clinical heterogeneity and natural history in 39 individuals in 9 families and 16 sporadic cases. Am J Hum Genet. 1991;49:133 (A676).

38. Selvanathan SK, Shenton A, Ferner R, et al. Further genotypephenotype correlations in neurofibromatosis type 2. Clin Genet. 2009;77(2):163-70.

39. Evans DGR, Trueman L, Wallace A, Mason S, Strachan T. Genotype phenotype correlations in NF2 (NF2): evidence for more severe disease associated with truncating mutations. J Med Genet. 1998;35(6):450-5.

40. Patronas NJ, et al. Intramedullary and spinal canal tumors in patients with neurofibromatosis 2: MR imaging findings and correlation with genotype 1. Radiology. 2001;218(2):434-42.
41. Baser ME, et al. The location of constitutional neurofibromatosis 2 (NF2) splice site mutations is associated with the severity of NF2. J Med Genet. 2005;42(7):540-6.

42. Bourn D, et al. Germline mutations in the neurofibromatosis type 2 tumour suppressor gene. Hum Mol Genet. 1994;3(5):813-6.

43. Mautner V-F, Baser ME, Kluwe L. Phenotypic variability in two families with novel splice-site and frameshift NF2 mutations. Hum Genet. 1996;98(2):203-6.

44. Baser ME, et al. Phenotypic variability in monozygotic twins with neurofibromatosis 2. Am J Med Genet. 1996;64(4):563-7.

45. Bruder CEG, Ichimura K, Blenow E, Ikeuchi T, Yamaguchi T, Yuasa Y, Collins VP, Dumanski JP. Severe phenotype of the neurofibromatosis type 2 gene in patients with a $7.4 \mathrm{Mbp}$ constitutional deletion on chromosome 22: possible localization of a neurofibromatosis type 2 modifier gene. Genes Chromosom Cancer. 1999;25:184-90.

46. Zucman-Rossi, Jessica, et al. NF2 gene in neurofibromatosis type 2 patients. Human molecular genetics 1998; 7(13): 2095-2101.

47. Evans DGR, Maher ER, Baser ME. Age related shift in the mutation spectra of germline and somatic NF2 mutations: hypothetical role of DNA repair mechanisms. J Med Genet. 2005;42(8):630-2.

48. Gonzalez-Gomez P, Bello MJ, Alonso ME, et al. CpG island methylation in sporadic and neurofibromatis type 2-associated Schwannomas. Clin Cancer Res. 2003;9(15):5601-6.

49. Lomas J, Bello MJ, Arjona D, Alonso ME, Martinez-Glez V, Lopez-Marin I, Aminoso C, de Campos JM, Isla A, Vaquero J, Rey JA. Genetic and epigenetic alteration of the $N F 2$ gene in sporadic meningiomas. Genes Chromsom Cancer. 2005;42(3):314-9.

50. MacCollin M, Chiocca EA, Evans DG, Friedman JM, Horvitz R, Jaramillo D, Lev M, Mautner VF, Niimura M, Plotkin SR, Sang $\mathrm{CN}$, Stemmer-Rachamimov A. Roach ES diagnostic criteria for Schwannomatosis. Neurology. 2005;64(11):1838-45.

51. - Smith MJ, Kulkarni A, Rustad C, Bowers NL, Wallace AJ, Holder SE, Heiberg A, Ramsden RT, Evans DG. Vestibular Schwannomas occur in Schwannomatosis and should not be considered an exclusion criterion for clinical diagnosis. Am J Med Genet. 2012; 158(1): 215-9. This study questioned whether the exclusion of VS from the clinical diagnosis of Schwannomatosis is justified.

52. Smith MJ, Isidor B, Beet $\mathrm{C}$ et al. Mutations in LZTR1 add to the complex heterogeneity of Schwannomatosis. Neurology. in press.

53. Woods R, Friedman JM, Evans DGR, Baser M, Joe H. Exploring the '2-Hit Hypothesis' in NF2: tests of 2-Hit and 3 Hit models of vestibular Schwannoma development. Genet Epidemiol. 2003;24(4):265-72.

54. Warren C, James LA, Varley JM, Ramsden RT, Evans DG. Identifying recurrent regions of chromosome loss and gain in 76 vestibular Schwannomas using comparative genomic hybridisation (CGH). J Med Genet. 2003;40(11):802-6.

55. Torres-Martin M, Lassaletta L, San-Roman-Montero J, De Campos JM, Isla A, Gavilan J, Melendez B, Pinto GR, Burbano RR, Castresana JS, Rey JA. Microarray analysis of gene expression in vestibular Schwannomas reveals SPP1/MET signaling pathway and androgen receptor deregulation. Int J Oncol. 2013;42(3):848-62.

56. Fong B, et al. The molecular biology and novel treatments of vestibular Schwannomas: a review. J Neurosurg. 2011;115(5):906-14.

57. Lutchman M, Rouleau GA. The neurofibromatosis type 2 gene product, Schwannomin, suppresses growth of NIH 3T3 cells. Cancer Res. 1995;55(11):2270-4.

58. Pelton PD, Sherman LS, Rizvi TA, Marchionni MA, Wood P, Friedman RA, Ratner N. Ruffling membrane, stress fiber, cell 
spreading and proliferation abnormalities in human Schwannoma cells. Oncogene. 1998;17(7):2195-209.

59. Welling DB, et al. cDNA microarray analysis of vestibular Schwannomas. Otol Neurotol. 2002;23(5):736-48.

60. Plotkin SR, et al. Hearing improvement after bevacizumab in patients with neurofibromatosis type 2. $\mathrm{N}$ Engl J Med. 2009;361(4):358-67.

61. - Plotkin SR, Merker VL, Halpin C, Jennings D, McKenna MJ, Harris GJ, Barker FG. Bevacizumab for progressive vestibular Schwannoma in neurofibromatosis type 2. Otol Neurotol. 2012; 33(6):1046-52. An early study of extended follow-up of patients with aggressive VS showing clinical benefit of treatment with Bevacizumab.

62. Nunes FP, et al. Bevacizumab treatment for meningiomas in NF2: a retrospective analysis of 15 patients. PloS One. 2013;8(3): e59941.

63. Curto M, Cole BK, Lallemand D, Liu CH, McClatchey AI. Contact-dependent inhibition of EGFR signaling by Nf2/Merlin. J Cell Biol. 2007;177(5):893-903.

64. Evans DG, Kalamarides M, Hunter-Schaedle K, et al. Consensus recommendations to accelerate clinical trials for neurofibromatosis type 2. Clin Cancer Res. 2009;15(16):5032-9.

65. Wong HK, Lahdenranta J, Kamoun WS, et al. Anti-vascular endothelial growth factor therapies as a novel therapeutic approach to treating neurofibromatosis- related tumors. Cancer Res. 2010;70(9):3483-93.

66. Henry J, Bala A, Freeman S et al (2012) Bevacizumab: an effective treatment for spinal and peripheral nerve Schwannomas associated with neurofibromatosis type II and Schwannomatosis. 15th International Symposium on Pediatric Neuro-Oncology. Neuro-oncology 14 (Suppl. 1): 19-19.

67. Sawyers Charles. Targeted cancer therapy. Nature. 2004; 432(7015):294-7.
68. Scott Andrew M, Wolchok Jedd D, Old Lloyd J. Antibody therapy of cancer. Nat Rev Cancer. 2012;12(4):278-87.

69. Björkholm M, et al. Success story of targeted therapy in chronic myeloid leukemia: a population-based study of patients diagnosed in Sweden from 1973 to 2008. J Clin Oncol. 2011;29(18): 2514-20.

70. Merel P, et al. Screening for germ-line mutations in the NF2 Gene. Genes Chromosom Cancer. 1995;12(2):117-27.

71. Kluwe L, et al. Identification of NF2 germ-line mutations and comparison with neurofibromatosis 2 phenotypes. Hum Genet. 1996;98(5):534-8.

72. Ruttledge MH, Andermann AA, Phelan CM, Claudio JO, Han FY, Chretien N, Rangaratnam S, MacCollin M, Short P, Parry D, Michels V, Riccardi VM, Weksberg R, Kitamura K, Bradburn JM, Hall BD, Propping P, Rouleau GA. Type of mutation in the neurofibromatosis type 2 gene (NF2) frequently determines severity of disease. Am J Hum Genet. 1996;59:331-42.

73. Parry DM, et al. Germ-line mutations in the neurofibromatosis 2 gene: correlations with disease severity and retinal abnormalities. Am J Hum Genet. 1996;59(3):529.

74. Kluwe L, MacCollin M, Tatagiba M, Thomas S, Hazim W, Haase W, Mautner VF. Phenotypic variability associated with 14 splicesite mutations in the NF2 gene. Am J Med Genet. 1998;77(3): 228-33.

75. Baser ME, Makariou EV, Parry DM. Predictors of vestibular Schwannoma growth in patients with neurofibromatosis Type 2 . J Neurosurg. 2002;96(2):217-22.

76. Baser ME, Kuramoto L, Joe H, Kuramoto L, Joe H, Friedman JM, Wallace AJ, Ramsden RT, Evans DG. Genotype-phenotype correlations for nervous system tumors in neurofibromatosis 2: a population-based study. Am J Hum Genet. 2004;75(2):231-9. 